\title{
REVISIÓN TAXONÓMICA DEL GÉNERO STEVENSIA POIT.
}

\author{
A. BORHIDI \\ Instituto de Ecología y Botánica Academia de Ciencias de Hungría \\ H-2163 Vácrátót, Hungría; E-mail: borhidi@botanika.hu \\ Grupo de Investigaciones de Adaptación Biológica de la Universidad de Pécs \\ H-7624 Pécs, Ifjúság u. 6, Hungría; E-mail: borhidi@ttk.pte.hu
}

(Received 18 July, 2001)

\begin{abstract}
Stevensia Poit. (Rubiaceae, Rondeletieae) is an endemic genus of the Hispaniola island in the West Indies containing nine species according to Liogier (1995). Within the framework of the Flora of the Greater Antilles project a new taxonomic revision has been made with amplified descriptions of the taxa and with the addition of two new species, Stevensia farinosa spec. nov. and Stevensia trilobata spec. nov. A new analytic key for the genus is also carried out.
\end{abstract}

Kew words: Stevensia, new species, critical revision, analytic key

\section{INTRODUCCION}

El género Stevensia Poit. (Rubiaceae, Rondeletieae) es un género endémico de la Isla de la Española incluyendo nueve espécies según Liogier (1995). En el marco del proyecto Flora de las Antillas Mayores ha sido elaborado una nueva revisión crítica taxonómica del género añadiendo descripciones de dos especies nuevas, Stevensia farinosa spec. nova y Stevensia trilobata spec. nova. Una clave analítica más detallada y descripciones ampliadas de los taxa ya previamente conocidos estan presentadas también.

\section{STEVENSIA Poit., Ann. Mus., Paris, 4: 235. (1804)}

Arbustos o arbolitos pubescentes y a menudo resinosos, las ramitas cilíndricas; estípulas connadas en vaína tubular con lóbulos triangulares interpeciolares obtusos y persistentes; hojas opuestas, corto-pecioladas, coriáceas. Floras blancas, solitarias en las axilas, pedunculadas; brácteas 2; cáliz cerrado antes del antesis y encerrando la corola, ovoideo-oblongo, rostrado-acuminado, en la antesis bi- o trífido, lóbulos iguales o desiguales, estrigosos por dentro, finalmente caedizos; corola asalvillada, el tubo cilíndrico, apenas ensanchado distalmente, glabropor dentro, la garganta 
desnuda, lóbulos 5-7, imbricados en el botón, redondeados en el ápice, carnosos, extendidos. Estambres 5-7, insertos en la garganta de la corola; filamentos muy cortos, anteras dorsifijas, oblongo-lineares, emarginadas en la base, obtusas en el ápice, inclusas; estilo glabro, bífido o bilobulado, lóbulos lineares, truncados; disco anular, ovario obovoideo, subcomprimido, hirsuto, 2-locular; óvulos numerosos, multiseriados, las placentas peltadas; cápsula pequeña, globosa, exocárpio crustáceo, endocarpio subóseo, loculicidamente bivalvo, valvas bipartidas; semillas numerosas, ovoideo-oblongas, reticuladas, aladas; embrión diminuto. Género endémico de Española con 11 espécies.

1a Ramitas glabras, fruto glabro, pedicelos de 5-12 m 2

1b Ramitas pelositas o papilosas 4

2a Tubo estipular truncado de $2-3 \mathrm{~mm}$, brácteas formando tubo truncado de $1.5 \mathrm{~mm}$

3. S. ebracteata

2b Estípulas connadas en la base, triangular-agudos a deltoideos

3a Brácteas hojosas, linear-lanceoladas, de 7-10 mm, estípulas de $5 \mathrm{~mm}$ incluyendo la parte connada, hojas de hasta $8 \mathrm{~cm}$

7. S. hotteana

3b Brácteas connadas en un tubo, los lóbulos diminutos, estrechamente triangulares, estípulas de $2 \mathrm{~mm}$, los lóbulos deltoideos, hojas de hasta $12 \mathrm{~cm}$

6. S. grandiflora

4a Hojas elípticas a oblongas, de hasta $1.5 \mathrm{~cm}$, redondeadas a obtusas en el ápice, corola de $8 \mathrm{~mm}$, flores sésiles o casi $\quad$ 8. S. minutifolia

4b Hojas agudas a acuminadas en el ápice, de 2.5-10 cm, corola de 1-2.5 $\mathrm{cm}$

5a Ramitas usualmente no resinosas, corola de $20-25 \mathrm{~mm}$, hojas pardas en el envés, glabras

4. S. ekmaniana

5b Ramitas resinosas, corola de 6-20 mm, hojas blancuzcas a grisaceas en el envés

6a Hojas con nervios laterales 15-20 pares, densamente dispuestas en el envés

1. S. aculeolata

6b Hojas con nervios laterales de 6-14 pares en el envés 
7a Hojas redondeadas a subacorazonadas en la base, glabras en el envés

9. S. ovatifolia

$7 \mathrm{~b}$ Hojas agudas en la base, pubescentes a tomentosas en el envés $\quad 8$

8a Hojas linear-lanceoladas de $4-10 \mathrm{~cm}$ de largo 10. S. samanensis

8b Hojas elípticas, obovadas a oblanceoladas de hasta $4.5 \mathrm{~cm}$ de largo

9a Tubo estipular de $1 \mathrm{~mm}$, lóbulos de la corola 6-7

2. S. buxifolia

9b Tubo estipular de 1.5-2.5 mm de largo, lóbulos de la corola $5 \quad 10$

10a Tubo de la corola de 6-7 mm de largo, lóbulos casi de igual largo

11. S. trilobata

10b Tubo de la corola 10-12 mm de largo, lóbulos 3-4 veces más cortos

5. S. farinosa

\section{Stevensia aculeolata Alain, Phytologia 70(3): 153. (1991)}

Arbusto de $1.5 \mathrm{~m}$, las ramitas muy resinosas, retrorso estrigosas, aculeoladas; estípulas subconnadas en la base, de $4 \mathrm{~mm}$, la base triangular, cuspidadas, pulverulentas, pecíolo de $3 \mathrm{~mm}$, hojas estrechamente elíptico-oblongas a lanceoladas, de $2.5-5 \mathrm{~cm}$ por $5-15 \mathrm{~mm}$, estrechadas hacia la base redondeada, subacorazonada a obtusa, agudas a corto-acuminadas en el ápice, nervios laterales 15-20 pares, promínulos en el envés, glabras en el haz, densamente pardo claro y tomentosas en el envés, el margen recurvo, coriáceas. Flores sésiles, bractéolas 2 oblongo-elípticas de 6-8 mm, largo acuminadas, pubérulas por fuera, cáliz aovado-cuspidado en el botón, lóbulos 2 estrechamente aovado-cuspidados de 4-5 mm, ciliados; corola blanca de 12-14 mm, densamente retrorso-serícea por fuera, lóbulos 6 estrechamente elípticos, de $3 \mathrm{~mm}$, cápsula esferoidal de $4 \mathrm{~mm}$, pelosita por fuera, coronada por los lóbulos del cáliz. - Sobre rocas calcareas al nivel del mar; RD: Bahía de Samaná, Los Haitises.

Holotipo: REP. DOMINICANA: Bahía de Samaná, Los Haitises, leg.: A. \& P. Liogier, 26329, 19.01.1977, NY!; isotipo: NY!

Specimina examinata: REP. DOMINICANA: Bahía de Samaná, Los Haitises, Prov. El Seibo, entre Cueva de Arena y la Boca del Infierno. Coord.: $19^{\circ} 05^{\prime} \mathrm{N}, 69^{\circ} 27^{\prime} \mathrm{W}$, leg.: T. Zanoni, M. Mejía, J. Pimentel y R. García, 34395, 25.04.1985. - Ibidem, T. Zanoni, M. Mejía, J. Pimentel y R. García, 35958, 08.01.1986. 
2. Stevensia buxifolia Poit., Ann. Mus., Paris, 4: 235. (1804)

(Syn.: Rondeletia poitaei Grisebach p.p., quoad plantae dominicanae).

Arbusto de hasta $3.6 \mathrm{~m}$, las ramitas corto-pelosas, algo resinosas, vaína estipular de $1 \mathrm{~mm}$, lóbulos triangulares de $1 \mathrm{~mm}$, pelósitos; hojas corto-pecioladas, estrechamente elípticas a oblongas de $2.5-4.5$ por $0.8-1.5 \mathrm{~cm}$, obtusas, agudas u corto-acuminadas en el ápice estrechadas hacia la base aguda, los nervios laterales obsoletos en el haz, 8-10 pares promínulos y negruzcos en el envés, reticulado-anastomosados, el haz negruzco y brilloso, el envés blanco- a gris-tomentoso, el margen a menudo recurvo. Flores axilares, pedicelos tomentosos de hasta $2 \mathrm{~mm}$, brácteolas unidas en la base en un tubo tomentoso de $2 \mathrm{~mm}$, lóbulos 2-4, agudos de $1.5 \mathrm{~mm}$; cáliz de 5 $\mathrm{mm}$, acuminado en el botón, tomentoso, abriéndose en 2 lóbulos acuminados, blanco-seríceos por dentro; corola de $1 \mathrm{~cm}$, retrorso-blanco-serícea por fuera, lóbulos 6-7, obovados, redondeados en el ápice, glabros por dentro, cápsula globosa de 3-5 mm, hirsutula distalmente en el resto tomentosa. Endémica en toda la Isla Española, Chacuey.

Specimina examinata: REP. DOMINICANA: entre Santiago Rodriguez y La Leonor. Leg.: Alain H. Liogier, 13244, 22-23.10.1968. - Prov. Dajabón, Rio de las Caritas Partido, alt. 120 m, leg.: Alain H. Liogier, 16263, 05.10.1969, NY. - Prov. Dajabón, Orillas del Rio, leg. M. Colella, R. García y J. Pimentel, 1329, 18.06.1989. - Jaiqui Picado, 20 km Oeste de Santiago, alt. 300-400 m, leg.: Alain H. Liogier, 15585, 06.07.1969, NY. - Prov. Santiago, Distr. San José de las Matas, Arroyo Vallecito Jicomé, leg.: E. J. Valeur, 355, 12.01.1930, NY. - Prov. Santiago, Distr. San José de las Matas, Road to Loma Bajita Jicomé, leg.: E. J. Valeur, 820, 30.07.1930, NY. - Prov. Montecristi, Cordillera Septentrional, Sabana Cruz, coord.: $19^{\circ} 49^{\prime} \mathrm{N}$,

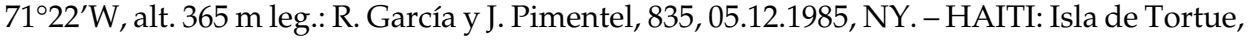
between La Vallé and La Rosetiere in coastal cliffs, leg.: E. L. Ekman, 20.05.1925, H-4059, S, NY.

\section{Stevensia ebracteata Urb. et Ekm., Ark. f. Bot., 24(4): 42. (1931)}

Arbusto, ramas resinosas glabras; estípulas connadas en un tubo truncado de 2-3 mm; pecíolos de $7-13 \mathrm{~mm}$, hojas aovadas a aovado-elípticas, de 5-8 por 2-3.5 cm, corto-acuminadas en el ápice obtusito, redondeadas a algo estrechadas en el pecíolo en la base, nervios laterales 8-9 pares, poco visibles en el haz, prominentes en el envés, el margen algo recurvo, brillosas en el haz, grises y glabras en el envés, coriáceas. Flores axilares, pedúnculos de 5-10 mm; brácteolas connadas en un tubo truncado de 1.5 $\mathrm{mm}$; botónes florales aovados con rostro de 2.5-4 mm, deciduo, glabros; ló- 
bulos del cáliz aovados de $8 \mathrm{~mm}$, corola blanca, el tubo retrorso-seríceo; cápsula globosa, glabra de 7-8 mm, semillas lanceoladas, crenuladas, pardas de 1.5-2 mm. - Bosques húmedos, endémica en la RD.

Holotipo: REP. DOMINICANA: Cordillera Central, Villa Altagracia, Loma Morión Chicle, leg.: E. L. Ekman, 06.01.1930, H-14250, S; isotipo: NY!

4. Stevensia ekmaniana Urb., Ark. f. Bot., 24(4): 42. (1931)

Arbolito, ramitas más o menos comprimidas, casi sin resina, pelositas a glabrescentes; estípulas triangular-lanceoladas, de 4-5 mm, acuminadas, connadas solo en la base; pecíolos de $2-6 \mathrm{~mm}$, hojas lanceoladas a obovado-oblongas de 4-7 por 1.5-2.5 cm, estrechadas a corto-acuminadas en el ápice agudo, agudas en la base, nervios laterales 8-10 pares, poco visibles en el haz, prominentes y reticulados en el envés, negruzcas en el haz, pardas en el envés, glabras, cartáceas; pedúnculos de 4-7 mm, brácteolas linear-acuminadas, la parte libre de $4 \mathrm{~mm}$, triangular; cáliz aovado en el botón, rostrado de 12-15 mm, pulverulento-pelosito, lóbulos 2 desiguales, 3-nervios; corola blanca de 22-24 mm, retrorso-serícea, lóbulos 5, oblongo-lineares de $10 \mathrm{~mm}$; cápsulas globosas de hasta $7 \mathrm{~mm}$, pelositas, semillas lanceoladas a romboideas de 1.5-2 mm. - Rocas calcareas, endémica en Haiti.

Holotipo: HAITI, Massif du Nord, Bayeux, Morne Brigand, leg.: E. L. Ekman, H-2849, S.

\section{Stevensia farinosa Borhidi spec. nova, hoc loco}

Arbusto, ramitas diminutamente pelosas, resinosas, 4-angulosas o anguste 4-aladas; estípulas connadas en la base en un tubo de 1-1.5 $\mathrm{mm}$, la parte libre obovada, redondeada en el ápice de $0.5-1 \mathrm{~mm}$, brevemente corto-barbada en el margen; pecíolos de $0.5-3 \mathrm{~mm}$ brevemente hirsutos; hojas oblanceoladas, de $2.5-4$ por $0.8-1.5 \mathrm{~cm}$, agudas y mucronaditas en el ápice, atenuadas en la base estrechandose en el pecíolo; nervio medio hundido en el haz, prominente y brevemente pubérulo en el envés, nervios laterales 8-11 pares, hundidos en el haz, prominulos, negruzco-pardos y densamente reticulado-anastomosados en el envés, la lamina negro-brillosa resinosa, rugulosa y glabra en el haz, verdoso-blanca y densamente pulverulento-tomentosa en el envés, el margen anchamente revoluto, cartáceas; 
flores axilares solitarias, pedúnculos de 1-4 $\mathrm{mm}$, angulosos, papiloso-rugosos, bractéolas 2, connadas triangulares de $1.5 \mathrm{~mm}$, la parte libre linear-subulada de 1-2 mm; cáliz elíptico en el botón, brevemente rostrado de hasta $1 \mathrm{~mm}$, el tubo de $1 \mathrm{~mm}$, lóbulos 3, aovados, de 1-3 mm, desiguales, uno más ancho con 2 nervios prominentes en el dorso, dos laterales más estrechos sin nervio, acuminados, densamente plateado-seríceos por dentro, adprimido pelosos por fuera; corola blanca de 12-15 mm densamente retrorso-serícea por fuera, el tubo estrecho, $10-12 \mathrm{~mm}$ de largo y $0.5-0.7 \mathrm{~mm}$ de diámetro, en la base, 1.5-2 mm de ancho en la garganta, lóbulos 5 obovados a suborbiculares de 3-4 mm de largo y $2.5-3 \mathrm{~mm}$ de ancho 3-4 veces

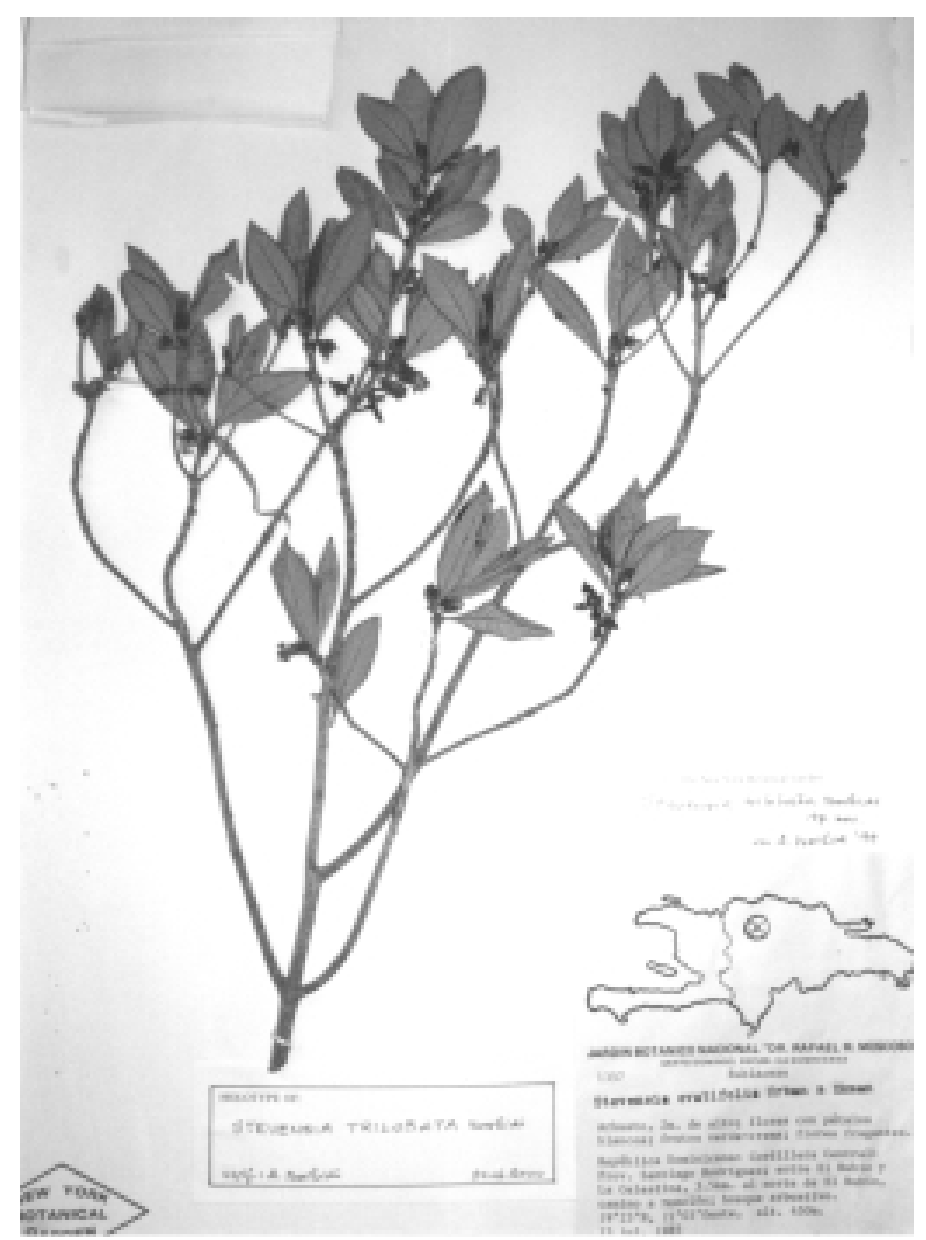

Fig. 1. Stevensia trilobata Borhidi spec. nov. Holotipo specimen, col.: M. Mejía et al., 1357, NY 
más cortos que el tubo; ovario globoso, pubérulo por fuera, 2-3 $\mathrm{mm}$ de diám., anillo glabro; cápsula esferoidal de 3-4 mm, loculicida, bivalva, pelosita por fuera.

Frutex, ramuli hornotini minute pilosi, resinosi, 4-angulati vel tenuiter 4-alati; stipulae basi connatae in tubum 1-1.5 $\mathrm{mm}$ longum pars libera eius obovata, apice rotundata, 0.5-1 mm longa margine breviter barbata; petiolum $0.5-3 \mathrm{~mm}$ longum, breviter hirsutum; folia oblanceolata, 2.5-4 cm longa et $0.8-1.5 \mathrm{~cm}$ lata, apice acuta et mucronulata, basi attenuata et in petiolum protracta; nervo medio supra impresso, subtus prominenti et brevissime pubescenti, lateralibus utroque latere 8-11 supra tenuiter impressis, subtus prominulis, nigrescentibus et dense

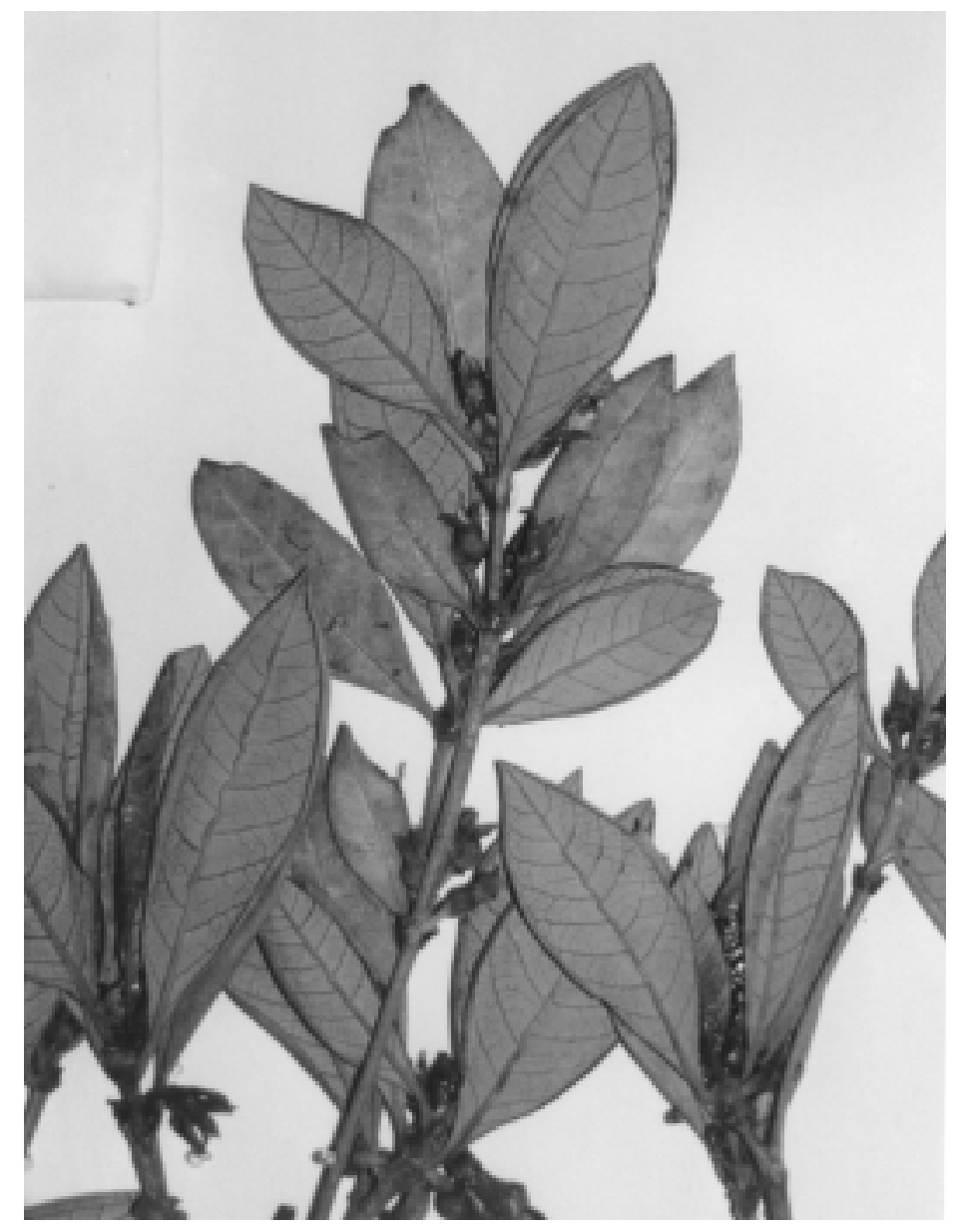

Fig. 2. Ramita fructifera de la Stevensia trilobata 
reticulato-anastomosantibus, limbo supra nigro, nitidulo resina induto, leviter ruguloso et glabro, subtus albo-virescenti et densissime pulverulento-tomentoso, margine late revoluto, cartaceo; flores axilares solitarii, pedunculi 1-4 mm longi, angulosi, papilloso-rugosi, bracteolae 2 connatae triangulares $1.5 \mathrm{~mm}$ longae, pars libera linear-subulata, 1-2 mm longa; calyx in alabastro ellipticus, breviter rostratus usque ad $1 \mathrm{~mm}$ longus, calycis tubus $1 \mathrm{~mm}$ longus, lobi 3, ovati, 1-3 mm longi, inaequales, unus latior dorso 2-nervis, duo angustiores enerves, acuminati, intus densissime argenteo-serícei, extus, adpresse pilosi; corolla alba, 12-15 mm longa, extus dense retrorso-serícea, tubus corollae tenuis, 10-12 mm longus, basi 0.5-0.7 $\mathrm{mm}$, in diametro, superne paullo dilatatus usque ad 1.5-2 mm, lobi 5 obovati vel suborbiculares, 3-4 mm longi et 2.5-3 mm lati, tubo 3-4-plo breviores; ovarium globosum, pubescens, 2-3 mm in diametro, anillum glabrum; capsula sphaeroidalis, 3-4 mm in diametro, loculicida, bivalva, extus sparse pilosa.

Holotipo: REP. DOMINICANA, entre Santiago y San José de Matas, leg.: L. R. Holdridge, No. 529, 16.12.1940, NY; isotipo: PRU.

\section{Stevensia grandiflora Alain, Phytologia 70(3): 154. (1991).}

Arbusto de unos $2 \mathrm{~m}$, ramitas glabras, resinosas; estípulas connadas en la base, aoad cuspidadas, ciliadas, de 3-3.5 mm, hojas oblongo-elípticas de $4.5-8$ por $1.5-3 \mathrm{~cm}$, acuminadas en el ápice, estrechadas en la base, nervios laterales 10-12 pares en el envés, láminas verde oscuras en el haz, blanco-grisáceas en el envés, glabras. Flores solitaras en las exilas, pedúnculos de $1 \mathrm{~cm}$, brácteas connadas formando cúpula de $1.5 \mathrm{~mm}$, lóbulos lineares de $2 \mathrm{~mm}$; botones florales elipsoideos de $4 \mathrm{~mm}$, el rostro de $4 \mathrm{~mm}$, lóbulos del cáliz 2-3-nervios, de hasta $1.5 \mathrm{~cm}$; corola blanca de $2.5 \mathrm{~cm}$, retrorso-serícea por fuera, lóbulos 6 oblongo-aovados de hasta $8 \mathrm{~mm}$; cápsulas globosas de $8 \mathrm{~mm}$ de diám., glabras, desnudas en el ápice. - Terrenos lateríticos, endémica en RD.

Holotipo: REP. DOMINICANA, La Manaclita, entre Bonao y La Vega, leg.: A. Liogier 15816, 29.06.1969, NY!

Specimina examinata: REP. DOMINICANA: Prov. La Vega-San Cristóbal Peravia, Cordillera Central, orillas del Rio Mahoma, coord.: $18^{\circ} 43.5^{\prime} \mathrm{N}, 70^{\circ} 22^{\prime} \mathrm{W}$, leg.: T. Zanoni, M. Mejía, J. Pimentel 22903, 26.08.1982. - REP. DOMINICANA: Prov. Duarte, San Francisco de Macorís, Cordillera Septentrional, Loma Quita Espuela. Coord.: $19^{\circ} 21^{\prime} \mathrm{N}, 70^{\circ} 90^{\prime} \mathrm{W}$, leg.: R. García, 1976, 15.04.1987. 
7. Stevensia hotteana Urb. et Ekm., Ark. f. Bot. 24(4): 41. (1931)

Arbusto, ramitas estriadas resinosas apicalmente, glabras; estípulas de $5 \mathrm{~mm}$, tubuloso-connadas en la base, la parte libre corto-triangular, aguda; pecíolos de 6-12 mm, hojas elíptico-oblongas a oblongo-lanceoladas, de 5-8 por 2-3 cm, corto-acuminadas en el ápice, agudas a obtusitas en la base, nervios laterales 10-13 pares, prominentes y anastomosados en el envés, las más jóvenes resinoso-brillosas, las adultas grises y glabras en el envés, coriáceas; pedúnculos de 7-12 $\mathrm{mm}$, brácteolas hojosas, linearlanceoladas a lanceoladas, acuminadas, 3-4-nervias, de 7-10 $\mathrm{mm}$; cáliz oblongo y rostrado en el botón, glabro, de $15 \mathrm{~mm}$, lóbulos 2 desiguales 1-nervios; corola no observada; cápsulas globosas de hasta $7 \mathrm{~mm}$, semillas lanceoladas a ovales de 1.5-2 mm. - En bosques, de Haiti, Massif de la Hotte, endémica.

Holotipo: HAITI, Massif de la Hotte, Jérémie, leg.: E. L. Ekman H-10222, S.

\section{Stevensia minutifolia Alain, Phytologia 70(3): 156. (1991)}

Arbusto de $2.5 \mathrm{~m}$, las ramitas resinosas y pelositas; estípulas corto-connadas en la base, triangulares, redondeadas, de $1.5 \mathrm{~mm}$ ciliadas; hojas elípticas a estrechamente elípticas de $1-1.5 \mathrm{~cm}$ por $3-5 \mathrm{~mm}$, redondeadas, obtusas o agudas en el ápice, agudas, obtusas a redondeadas en la base, nervios laterales 5-6 de cada lado en el envés, la superficie oscura en el haz, blanco-grisácea en el envés, glabras, cartáceas; flores axilares solitarias, pedicelos de hasta $1 \mathrm{~mm}$; brácteas connadas en vaina de $1 \mathrm{~mm}$, la parte libre subulada de $2 \mathrm{~mm}$; botón floral elíptico de $3 \mathrm{~mm}$, rostro de $2 \mathrm{~mm}$, lóbulos del cáliz elípticos, cuspidados de $3 \mathrm{~mm}$, papilosos por fuera, seríceos pro dentro; corola de 8-9 $\mathrm{mm}$, densamente retrorso-serícea por fuera, lóbulos 5 obovado-elípticos de $2 \mathrm{~mm}$, redondeados; cápsulas esferoidales de 4 mm de diám., pelositas por fuera. - Pinares, endémica.

Holotipo: HAITI: Massif de la Selle entre Furcy y Seguin, coord.: $18^{\circ} 26^{\prime} \mathrm{N}, 72^{\circ} 16^{\prime} \mathrm{W}$, leg.: M. Mejía y J. Pimentel, 24394, 17.11.1982, NY!; isotipo: NY!

Specimina examinata: REP. DOMINICANA: Sierra de Bahoruco, Aceitillar, Pedernales, leg.: Frank Votava y Alain H. Liogier, 103, febr. 1971, NY! 
9. Stevensia ovatifolia Urb. et Ekm., Ark. f. Bot. 20(5): 54. (1926)

Arbusto, ramitas papilosas, resinosas, cilíndricas; estípulas connadas en la base, la parte libre triangular aguda a obtusita de $2.5-3 \mathrm{~mm}$, pecíolos de 3-4 mm, hojas aovadas, de $1.5-4$ por $1.2-2 \mathrm{~cm}$, agudas a cortoacuminadas en el ápice, redondeadas a subacorazonadas en la base, nervios laterales 7-9 pares, prominentes y reticulado-anastomosados en el envés, glabras, verde-olivo en el haz, verde-cenizo en el envés, coriáceas; pedúnculos de $0.5 \mathrm{~mm}$, brácteolas 2 triangulares de $1 \mathrm{~mm}$; cáliz aovado en el botón, rostrado, lóbulos 2-3 aovados, acuminados, densamente seríceos por dentro de hasta $8 \mathrm{~mm}$; corola blanca fragante de 14-15 mm densamente retrorso-serícea por fuera, lóbulos 6 obovado-elípticos de $5 \mathrm{~mm}$; cápsula esferoidal de 4-5 mm, pelosita distalmente. - Suelos calcáreos, Haiti, endémica.

Holotipo: HAITI: Montagne Trou d'Eau, leg.: E. L. Ekman H-1064, S.

Specimina examinata: HAITI: Morne á Cabrits, leg.: E. L. Ekman H-5648, S. - Montagnes Noires, Dept. Centre: entre Parque Central de Mirebalais y Croix des Bouquets, coord.: $18^{\circ} 44^{\prime}$ N, $72^{\circ} 10^{\prime}$ W. leg.: T. Zanoni, M. Mejía y J. Pimentel 24011, 11.11.1982, NY!

\section{Stevensia samanensis Urb., Repert. Gen. Spec. Nov. 20: 351. (1924)}

Arbusto, ramitas densamente cubiertas de pelitos desiguales retrorsos, cilindricas; estípulas connadas en la base, la parte libre triangular acuminada de $6 \mathrm{~mm}$; pecíolos de 3-8 $\mathrm{mm}$, hojas lanceoladas a linear-lanceoladas de 4-10 por 1-2 cm, acuminadas en el ápice, agudas en la base, nervios laterales 10-14 pares, prominentes y reticulado-anastomosadas en el envés, peloso-rugosas en el haz, el envés griseo-tomentoso a glabrescente, cartáceas; pedúnculos de $2-3 \mathrm{~mm}$, brácteolas 2 lanceolineares de $8 \mathrm{~mm}$; sépalos 2, connados por $7 \mathrm{~mm}$ el más largo de $2 \mathrm{~cm}$, acuminado en el ápice, 5-nervio, el menor de $13 \mathrm{~mm}$, acuminado, 3-nervio; corola de $2 \mathrm{~cm}$ o más larga, densamente retrorso-serícea por fuera, lóbulos 7 obovados; fruto no observados. - Bosque húmedo, RD. Peninsula de Samaná, endémica.

Holotipo: REP. DOMINICANA: Peninsula de Samaná, Pilón de Azucar, leg.: W. L. Abbott, 2354, 6-13.05.1902, B+; isotipo: US, NY!

Specimina examinata: REP. DOMINICANA: Peninsula de Samaná, Pilón de Azucar, leg.: E. L. Ekman, H-14854, S. 


\section{Stevensia trilobata Borhidi spec. nova, hoc loco}

Arbusto, ramitas diminutamente papiloso-pelosas, resinosas, 4-angulosas o comprimidas; estípulas connadas en la base en un tubo de 1-1.5 $\mathrm{mm}$, la parte libre anchamente triangular aguda, brevemente apiculada de $0.5-1 \mathrm{~mm}$, ciliadas en el margen; pecíolos de $2-3 \mathrm{~mm}$, engrosados en la base, hojas obovadas, de 1.5-3.5 por 1-1.5 cm, agudas a corto-apiculadas y mucronaditas en el ápice, atenuadas en la base estrechandose en el pecíolo; nervios laterales 7-10 pares, prominentes, densamente reticulado-anastomosados y corto-pelosos en el envés, verde-claras en el haz, y ferruginoso-verdes en el envés, opacas en ambas caras, el margen revoluto, coriáceas; flores axilares solitarias, pedunculos de 4-7 $\mathrm{mm}$ angulosos, gruesos de 1.5-2 mm en diám., brácteolas 2 connadas triangulares de $1.5 \mathrm{~mm}$, la parte libre linear-lanceolada de $3 \mathrm{~mm}$; cáliz aovado en el botón, rostrado, el tubo de $1 \mathrm{~mm}$, lóbulos 3 aovados, de $2-4 \mathrm{~mm}$, desiguales, uno más ancho con 2 nervios prominentes en el dorso, dos laterales más estrechos uninervios o sin nervio, acuminados, densamente plateado-seríceos por dentro, estrigoso pelosos por fuera; corola blanca o color de crema, de 6-8 $\mathrm{mm}$ densamante retrorso-serícea por fuera, el tubo ancho y corto, 5-6 mm de largo y 2-3 mm de ancho, lóbulos 5 obovados de 3.5-4.5 mm apenas más cortos que el tubo; ovario globoso, pubescente por fuera, 2-3 mm de diám., anillo hirsuto; cápsula esferoidal de 5-6 $\mathrm{mm}$, loculicida, bivalva, pelosita por fuera.

Frutex usque ad 2 m altus, rami hornotini minute papilloso-pilosi, resina induti, 4-angulativel compressi; stipulae basi connatae in tubum 1-1.5 mm longum, pars libera eius late triangular-acuta, breviter apiculata 0.5-1 mm longa, margine ciliata; petiolum 2-3 $\mathrm{mm}$ longum basi dilatatum, folia obovata, $1.5-3.5 \mathrm{~cm}$ longa et 1-1.5 cm lata, ápice acuta et breviter apiculata et mucronatula, basim versus attenuata et in petiolum protracta; nervi laterales 7-10 pares, supra tenuissime impressi vel obsoleti, subtus bene prominentes, dense reticulato-anastomosantes et brevissime hirsuti, lamina supra clare viridis, subtus ferrugineo-viridis, utrinque opaca, margine revoluta, coriacea; flores axillares solitarii, pedunculi 4-7 mm longi, angulosi, crassi, 1.5-2 $\mathrm{mm}$ in diametro, bracteolae 2, triangulares $1.5 \mathrm{~mm}$ longae connatae, pars libera foliosa linear-lanceolata $3 \mathrm{~mm}$ longa; calyx ovatus in alabastro, rostratus, tubus calycis $1 \mathrm{~mm}$ longus, lobi 3, ovati, 2-4 mm longi, inaequales, unus latior dorso nervibus duabus prominentibus, duo laterales angustiores uninervi vel enervati, acuminati et apiculati, intus dense argenteo-sericei, extus strigoso-pilosi; corolla alba 6-8 $\mathrm{mm}$ longa, extus densissime retrorso-sericea, tubus latus et brevis, 5-6 mm longus et 2-3 mm latus, lobi 5 obovati, 3.5-4.5 mm 
longi et 2-3 mm lati, tubo paullo breviores; stamina 5 in faucem corollae inserta, ovarium globosum, extus pubescens, 2-3 mm in diametro, anillum hirsutum; capsula globosa 5-6 mm in diametro, loculicida, bivalva, extus pubescens. Semina triangularia, fusca, minute reticulata.

Holotipo: REP. DOMINICANA, Prov. Santiago Rodriguez, Cordillera Central, entre El Rubio y La Celestina, camino de Monción, coord.: $19^{\circ} 23^{\prime} \mathrm{N}, 71^{\circ} 03^{\prime} \mathrm{W}$, leg.: M. Mejía, J. Pimentel y R. García 1357, 15.07.1985, NY!; isotipo: NY!

\section{BIBLIOGRAFÍA}

Liogier, A. H. (1995): Rubiaceae. - In: La Flora de La Espańola. Vol. VII. 207-439. San Pedro de Macoris R. D., Universidad Central del Este. Vol. LXXI. Serie científica 28.

Urban, I. (1924): Stevensia samanensis. - Repert. Gen. Spec. Nov. 20: 351.

Urban, I. (1926): Stevensia ovatifolia Urb. et Ekm. - Ark. f. Bot. 20(5): 54.

Urban, I. (1931): Stevensia hotteana Urb. et Ekm. - Ark. f. Bot. 24(4): 41. 